\title{
URBAN PLANNING DESIGN AND SUSTAINABLE DEVELOPMENT OF FOREST BASED ON HEAT ISLAND EFFECT
}

\author{
WANG, X. H. ${ }^{1}-\mathrm{WU}, \mathrm{Y}^{2^{*}}-$ GONG, J. ${ }^{3}-\mathrm{LI}, \mathrm{B} .{ }^{4}-\mathrm{ZHAO}, \mathrm{J} . \mathrm{J} .{ }^{4}$ \\ ${ }^{I}$ College of Landscape Architecture and Arts, Northwest A \& F University, Yangling 712100, \\ China \\ ${ }^{2}$ School of Architecture, Chang'an University, Xi'an 710061, China \\ ${ }^{3}$ Jiangxi Urban and Rural Planning \& Design General Institute, Nanchang 330000, China \\ ${ }^{4} X i$ 'an Urban Planning \& Design Institute, Xi'an 710082, China \\ *Corresponding author \\ e-mail:wxhxbdx@sina.com; phone: +86-180-3219-7955 \\ (Received $18^{\text {th }}$ Mar 2019; accepted $17^{\text {th }}$ May 2019)
}

\begin{abstract}
Under the background of rapid development of urbanization, how to make rational use of land resources is the main content of urban planning design. The unreasonable distribution of urban land intensifies the influence range and intensity of urban heat island effect, and the cooling and humidification of urban vegetation can effectively alleviate the surface temperature of cities and towns. Under this trend, based on the study of urban heat island effect and in view of the ecological benefit of forest cities, this paper makes systematic planning for the green space pattern of Shijiazhuang City, and puts forward the optimization strategy to realize the sustainable development of the urban ecological environment. The results show that the urban heat island effect increases with the increase of the urban planning forest coverage, and the urban forest has a certain threshold to alleviate the urban heat island effect, so the patch arrangement of the forest should be controlled. The forest planning pattern in urban planning can be adjusted and optimized to increase the urban forest patch shape index, thereby increasing the coupling degree between forest vegetation and environment, and maximizing the reduction of heat island effect. This study provides a theoretical basis for minimizing the heat island effect in the process of urban planning.
\end{abstract}

Keywords: urban planning, forest, ecological benefits, heat island effect, planning pattern, environmental coupling

\section{Introduction}

Urbanization continues to develop rapidly, which aggravates the change in urban land use types and causes urban climate change such as temperature rise and humidity decrease in urban areas, particularly, the heat island effect in urban environmental problems (Ahmed et al., 2015). In the layout of urban planning, the effective measures to alleviate the heat island effect include urban forest, green land and water body, among which forests as the "dispatcher" of the nature exist in a large amount in the city, with flexibility in activity (Li et al., 2018). All trees in parks, residential areas, blocks and around roads are part of the urban forest. In order to maintain and improve the ecological environment, the necessity and importance of building forest cities are becoming increasingly apparent in urban planning (Wang et al., 2015; Kamruzzaman et al., 2018). The planning design of urban forests not only increases urban green coverage, but also plays an important role in protecting natural ecology and improving human living environment (Hyoungsub et al., 2018). 
The design and planning of urban forests has high social benefits, which promote the development of cultural education, enhance urban landscape leisure and improve the urban ecological environment (Gago et al., 2013). The systematic planning and arrangement urban forests can form a comprehensive environment for coordinated development with the cities, thereby better improving the urban ecology and living environment (Senanayake et al., 2013). The planning and design state of urban forests is mainly distributed in point, strip, ring and wedge shape, all of which input fresh air to the cities, improving urban climate, environment and ventilation conditions (Wonorahardjo, 2012). Urban forest plays a good role in regulating urban heat island effect. The surface temperature can be reduced by more than $15^{\circ} \mathrm{C}$ in urban forestcovered areas, and the body temperature under shade can be reduced by $3-5{ }^{\circ} \mathrm{C}$ (Weilin et al., 2017). However, due to the scarcity of available land resources in cities, it is difficult to improve the heat island effect in urban forest planning design. Therefore, it is an important research direction to optimize the urban forest design pattern and focus on the sustainable development of urban forests (Krüger and Emmanuel, 2013). Based on the study of urban heat island effect, this paper aims at the ecological benefit of forest cities, systematically plans the green space pattern of Shijiazhuang City, Hebei Province, China and puts forward the optimization strategies to realize the sustainable development of urban planning.

\section{Materials and methods}

The effective planning design of urban forests can improve the urban landscape. The ecological layout of urban forests should be combined with the natural topographic features of each urban area. The service radius of urban forests is the focus of urban planning design and also relates to the sustainable development of urban ecology (Jay and Schraml, 2013). GIS is a quantitative technical analysis method, and provides a more accurate technical method for the study of heat island effect and urban forest pattern planning in Shijiazhuang City.

There are many measures to alleviate the heat island effect through urban planning, such as greening, energy saving, water permeability, increasing the urban forest space, and strengthening the road forest penetration rate, all of which have the effect of cooling the cities. The overall layout of urban forests is based on local conditions, balanced, systematic, ecological and people-oriented (Madanian and Cost, 2017). Table 1 is the relevant indicators of the national forest city standard system, which requires the forest coverage rate of the built-up area not less than $17 \%$, the urban road forest penetration rate not less than $60 \%$, the extension rate of the shaded parking lots not less than $60 \%$, and the intensity of urban heat island effect less than $3{ }^{\circ} \mathrm{C}$.

\section{Results}

\section{Analysis of forest planning pattern in central urban area of Shijiazhuang City}

With the development of satellite remote sensing technology, the method of retrieving surface temperature is constantly updated, and the surface temperature is greatly influenced by forest vegetation index (VI). VI and the surface temperature are calculated as shown in Equations 1 and 2, respectively: 


$$
\begin{aligned}
& \mathrm{VI}=\frac{\mathrm{P}_{\mathrm{MIR}} \mathrm{P}_{\mathrm{Red}}}{\mathrm{P}_{\mathrm{NIR}} \mathrm{P}_{\mathrm{Red}}}
\end{aligned}
$$

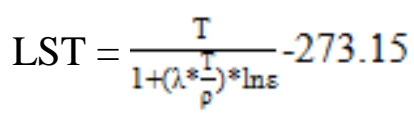

where $\rho$ NIR represents the reflectance of the near infrared band, $\rho$ Red represents the reflectance of the infrared band, $\lambda$ represents the central wavelength with a value of $11.80 \mu \mathrm{m}, \rho=1.438 \times 10-2 \mathrm{~K}, \varepsilon$ represents the emissivity value, when $\mathrm{VI}>$, take value of $1+0.027 \ln (\mathrm{VI})$, when $\mathrm{VI} \leq 0$, take value of 0.99925 .

Table 1. National forest city standard system related indicators

\begin{tabular}{c|c|c}
\hline \multirow{2}{*}{ Index } & \multicolumn{2}{|c}{ National forest city standard } \\
\cline { 2 - 3 } & Basic item & Promotion item \\
\hline Built-up area forest coverage rate & $\geq 17 \%$ & $\geq 20 \%$ \\
Built-up areas green coverage rate & $\geq 35 \%$ & $\geq 38 \%$ \\
Urban road forest penetration rate & $\geq 60 \%$ & $\geq 70 \%$ \\
Urban road green space compliance rate & $\geq 80 \%$ & $\geq 80 \%$ \\
Promotion rate of shade parking lot & $\geq 60 \%$ & $\geq 70 \%$ \\
Ecological and landscape restoration rate of damaged abandoned land & $\geq 75 \%$ & $\geq 80 \%$ \\
Urban heat island effect intensity & $\geq 3{ }^{\circ} \mathrm{C}$ & $\geq 2.5^{\circ} \mathrm{C}$ \\
\hline
\end{tabular}

Figure 1 shows the classification results of remote sensing images in Shijiazhuang City. The forest coverage area is $14 \%$. In recent year, Shijiazhuang City has persisted in planning and adjusting the layout of urban forests to increase urban vegetation coverage. Figure 2 is the relevant statistics of vegetation in the central urban area of Shijiazhuang City, and Figure $2 a$ is the per capita public green area in the urban areas. It can be seen that the per capita public green area does not increase linearly, but from 2012 to 2018, the per capita public green area in urban areas increased from $9.2 \mathrm{~m}^{2}$ to $10.4 \mathrm{~m}^{2}$; Figure $2 b$ shows there is a trend of annual increase in trees at the end of the year, but the growth area has been flat in the past two years, increasing to 15.88 million trees in 2018 from 13.22 million in 2012; Figure $2 c$ indicates that the number of vegetation trees on both sides of the sidewalks increased from 243,000 to 288,000. Although the area of per capita public green area and the vegetation and trees on both sides of sidewalks in each year do not show the trend of increasing year by year, the urban vegetation planning area increases greatly as a whole, which serves the purpose of alleviating the urban heat island effect. Figure 3 shows the forest coverage rate of some counties in Shijiazhuang City. Among the ten districts and counties in Shijiazhuang City, the forest coverage rate in 7 districts and counties exceeds $30 \%$, and is less than $30 \%$ in 3 districts and counties.

\section{Analysis on the benefits of urban forest cooling}

Figure 4 is a graph of superimposing urban forest distribution and surface temperature. In the figure, green is urban forest area. It is found that there is almost no heat island effect in green land location by GIS observation and the heat island effect still exists in areas without vegetation coverage. Figure 5 shows the trend of intensity change of heat island effect in some urban areas of Shijiazhuang City. It can be seen that the intensity of 
heat island effect in Xinhua, Zhengding, Wuji, Chang'an and Lingshou counties increased by $1.44{ }^{\circ} \mathrm{C}, 1.65^{\circ} \mathrm{C}, 1.2^{\circ} \mathrm{C}, 0.98^{\circ} \mathrm{C}$ and $1.0^{\circ} \mathrm{C}$ from 2004 to 2018 , respectively. The comparison of forest coverage rate and heat island intensity in some counties of Shijiazhuang City shows that the higher the urban forest coverage rate is, the smaller the increase value of urban heat island intensity is and the buffering effect of urban forests on ground cooling. However, due to the influence of urban planning distribution structure and vegetation coverage area, the heat island effect is obvious in areas far from urban forests. Therefore, in order to alleviate the urban heat island effect effectively, it is necessary to optimize the urban forest space construction in the process of urban planning, and improve the thermal effect space by changing the urban forest pattern.

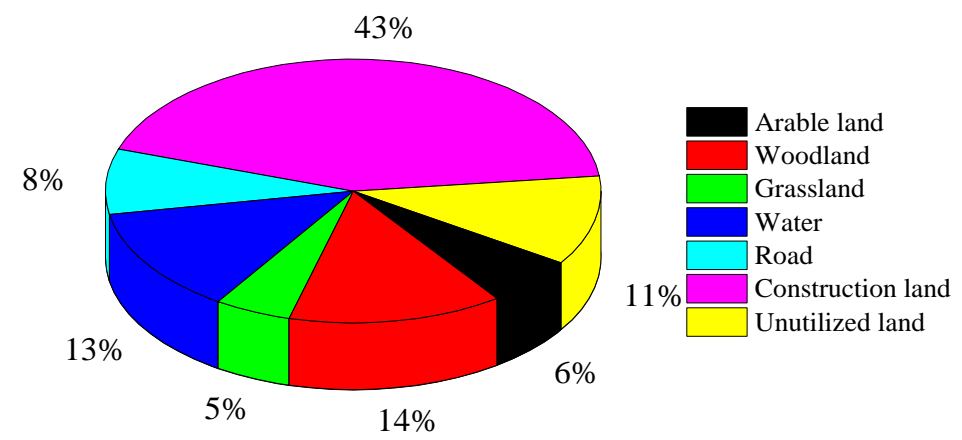

Figure 1. Statistics on classification results of remote sensing images in Shijiazhuang City

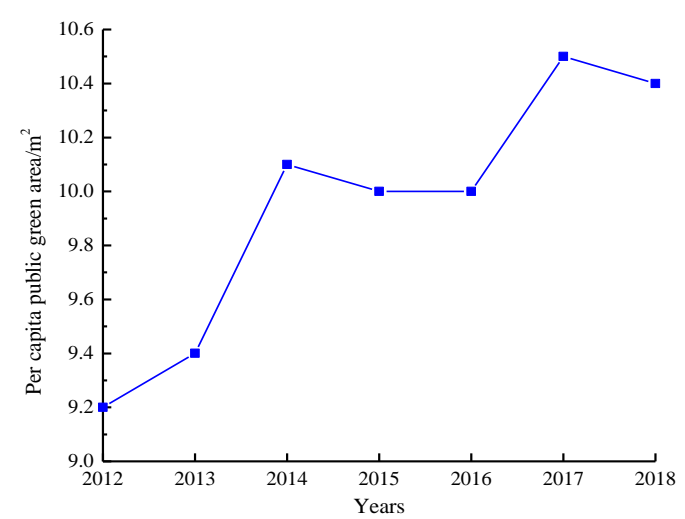

(a) Per capita public green area

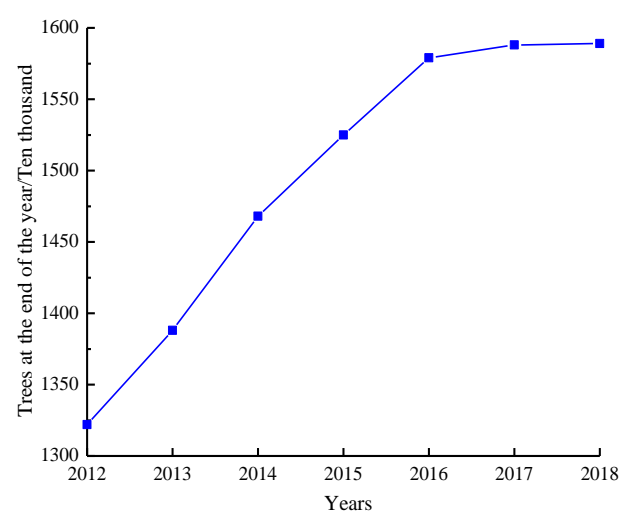

(b) Trees at the end of the year

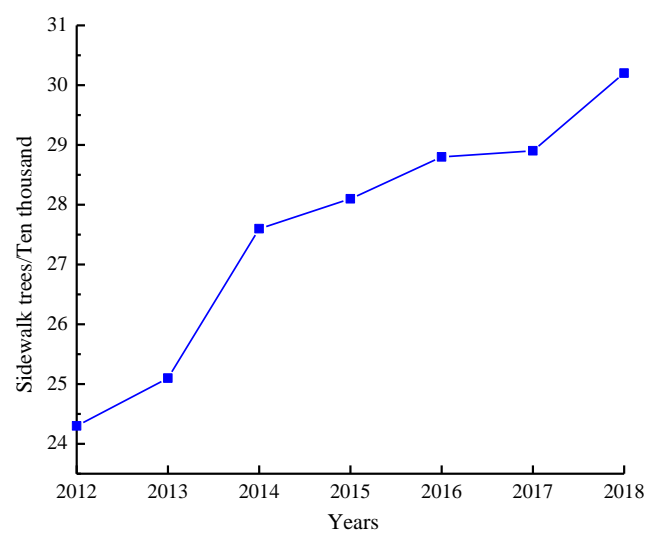

(c) Sidewalk trees

Figure 2. Vegetation related statistics in the central area of Shijiazhuang City 


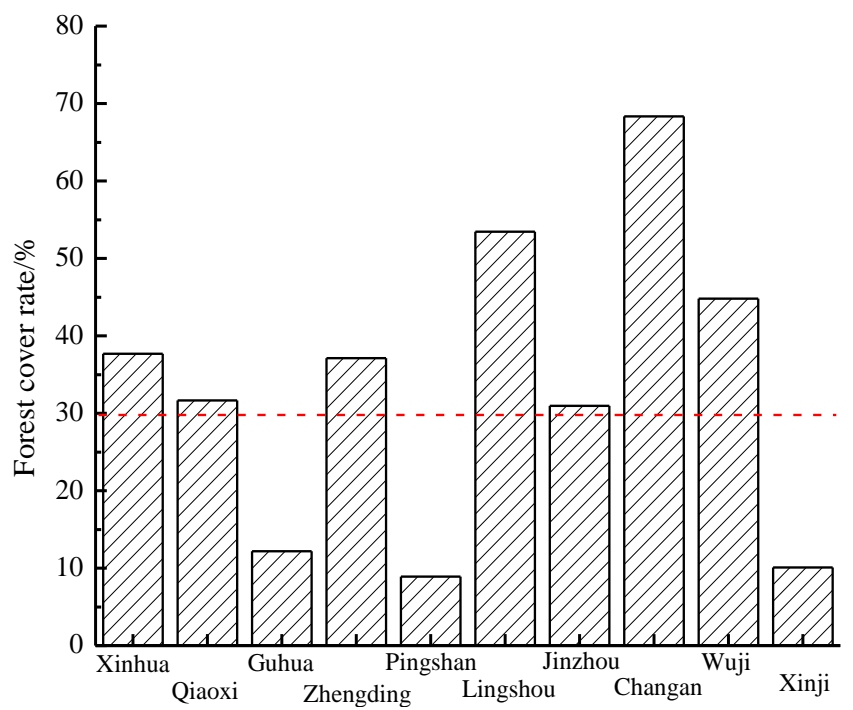

Figure 3. Forest coverage rate in some counties of Shijiazhuang City

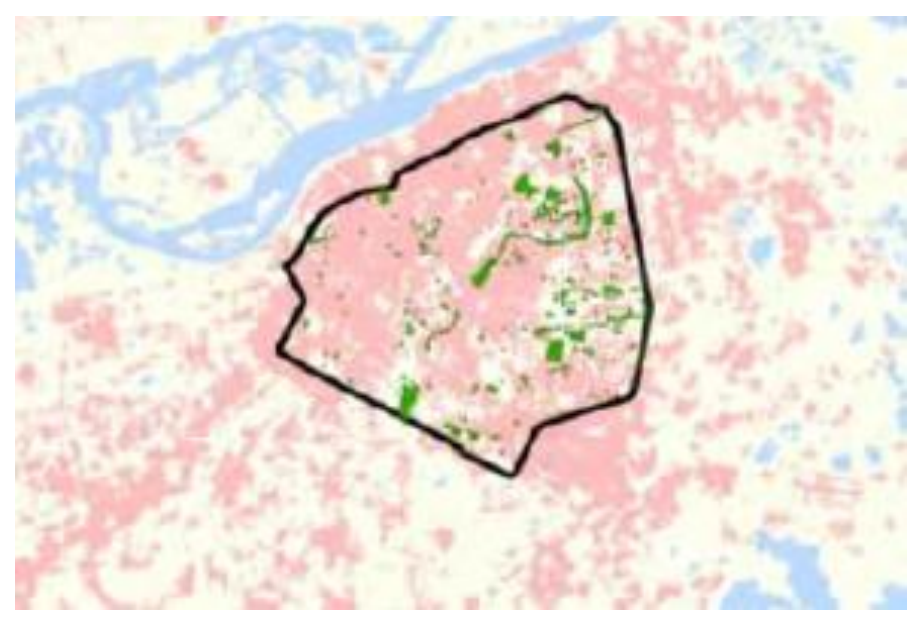

Figure 4. Urban forest distribution status and surface temperature overlay

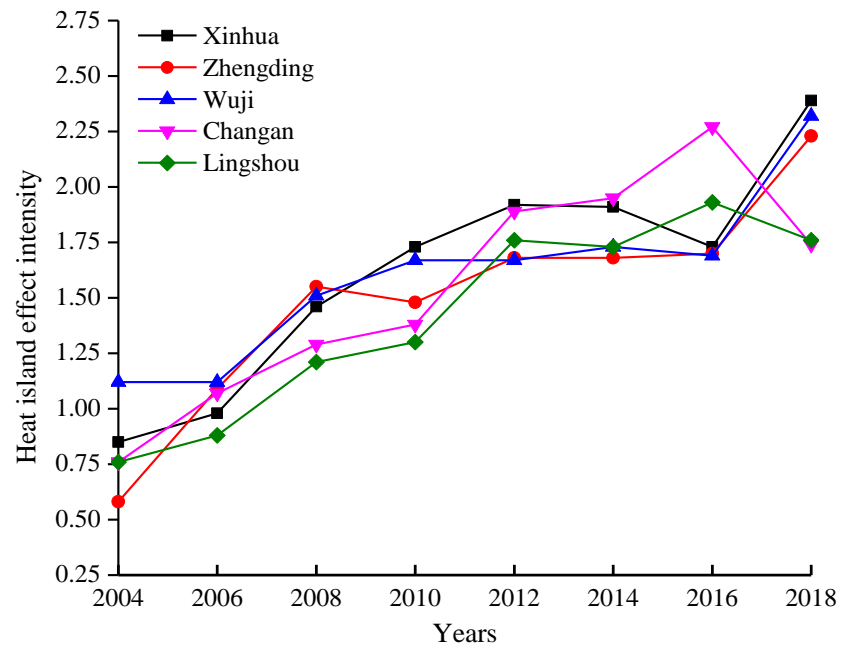

Figure 5. Trend map of heat island effect intensity in some urban areas of Shijiazhuang City 


\section{Discussion}

\section{Optimization measures of forest urban planning pattern in Shijiazhuang City}

The total amount and area of forests in urban planning design are constant, but the planning pattern can be adjusted and optimized. The spatial pattern of urban forests affects the type structure of urban forests and the intensity of urban heat island. Table 2 shows the type structure of urban forests in Shijiazhuang City. According to the type structure of urban forests, the proportion of park vegetation is the largest, accounting for $38.93 \%$ of the total vegetation area, followed by road vegetation and protective vegetation, while the vegetation area of residential areas is very small. However, the area of residential areas is the largest, which is the important reason for the uneven distribution of heat island effect. The planning area of vegetation in residential areas needs to be further improved in the process of urban planning.

Table 2. Type structure of urban forest in Shijiazhuang City

\begin{tabular}{c|c|c}
\hline Urban forest type & Area/hectare & Proportion/\% \\
\hline Park vegetation & 1263.76 & 38.93 \\
Unit affiliated vegetation & 119.46 & 3.68 \\
Residential areas vegetation & 190.55 & 5.87 \\
Road vegetation & 864.15 & 26.62 \\
Protective cover vegetation & 768.06 & 23.66 \\
Production vegetation & 40.25 & 1.24 \\
Total & 3246.23 & $100 \%$ \\
\hline
\end{tabular}

Figure 6 is the statistics of relevant data of forest cultivation in Shijiazhuang City in recent years, the area of forest cultivation and the number of forest cultivation fields all show a trend of decreasing. The urban forest has a certain threshold to alleviate the urban heat island effect, and the patch arrangement of the forest should be controlled. Figure 7 is a schematic diagram of the cooling efficiency of centralized and dispersed urban forests. Large area of urban forests breaking into parts can expand the scope of cooling and urban forests are evenly distributed with better benefits. The distance and quantity of urban forest patches should also be reasonably distributed, and the ideal distribution area is to maximize the influence range of the respective forest patches. However, the urban development should consider the layout of buildings, water bodies, roads, and others and it is not possible to arrange according to the ideal distribution. In order to maximize the benefits of urban forests, it is necessary to design the patch shape of the planning areas reasonably, increase the urban forest patch shape index, thus enhancing the coupling degree of forest vegetation and environment, and maximizing the reduction of heat island effect.

\section{Optimization measures for improving heat island effect of urban forests}

It is found that the urban heat island effect increases with the increase of urban forest coverage, so it is feasible to increase urban forest coverage. Figure 8 is a structural diagram of the urban planning and construction of Shijiazhuang, which is combining different urban forest landscape elements according to their own characteristics so as to build a characteristic forest city and improve the diversity of the urban ecosystem. 
Table 3 is the planning of artificial afforestation in Shijiazhuang City. In the future, the urban forest area will be expanded through the projects of mountain afforestation, conversion of farmland to forests, reforestation and afforestation subsidy.

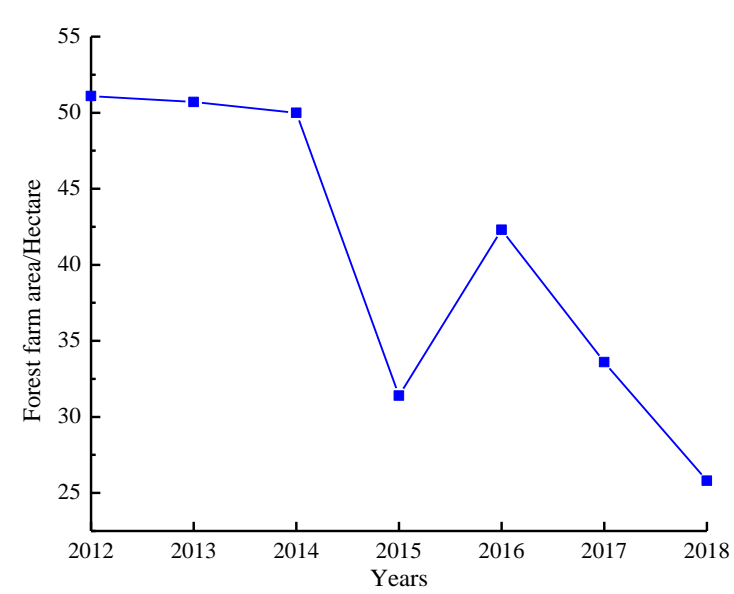

(a) Afforestation area

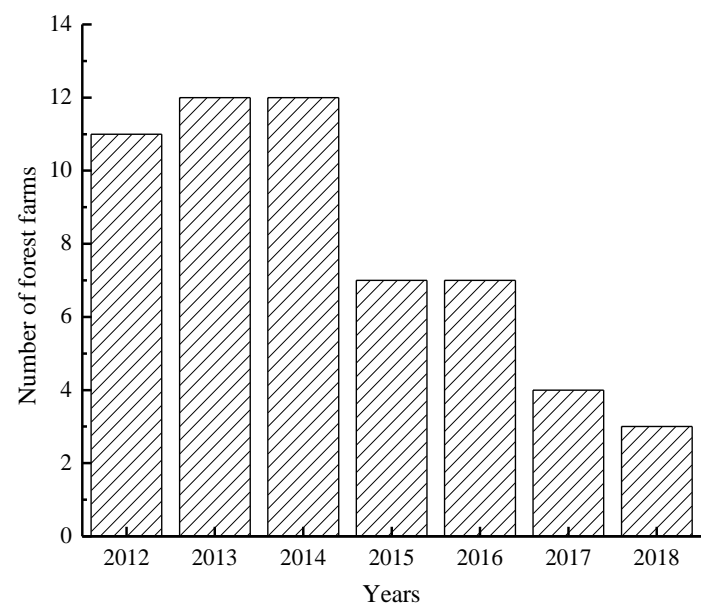

(b) Forest farms number

Figure 6. Statistics of related data on afforestation in Shijiazhuang City in recent years

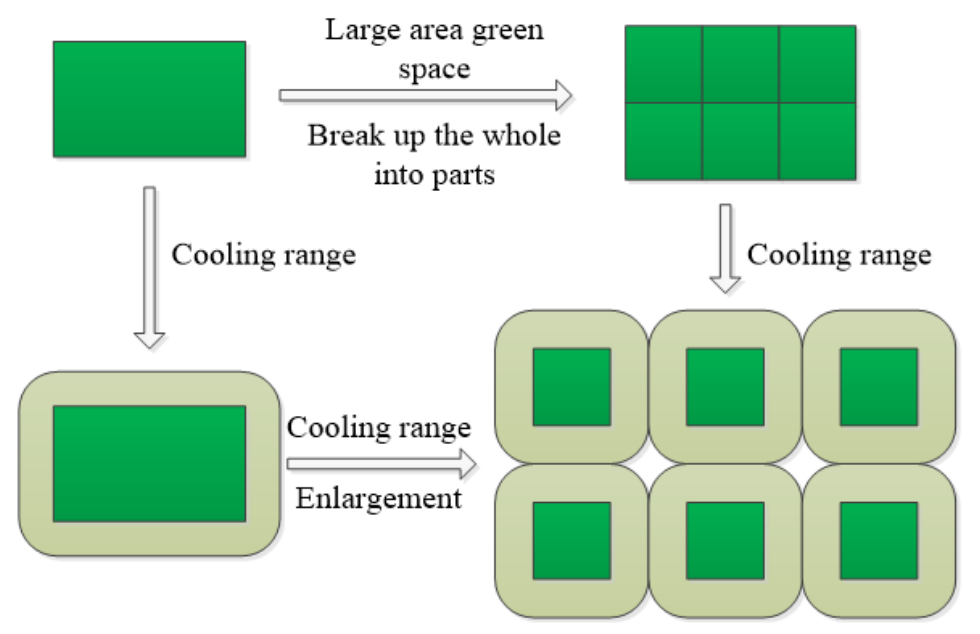

Figure 7. Schematic diagram of cooling and decentralized urban forest cooling benefits

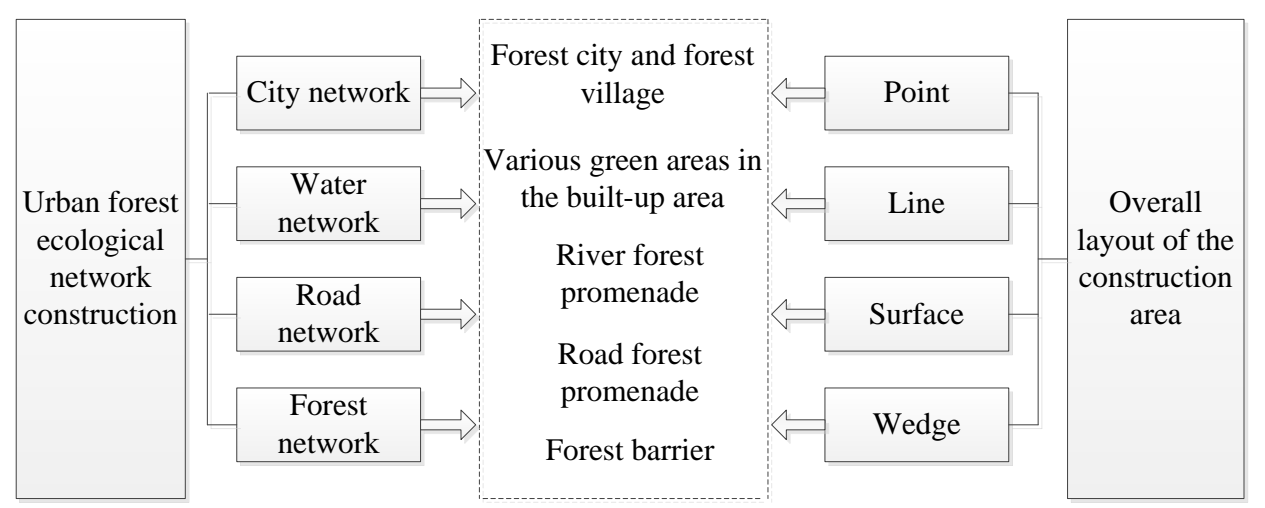

Figure 8. Shijiazhuang City urban planning construction structure 
Table 3. Shijiazhuang City afforestation planning

\begin{tabular}{c|c|c|c|c}
\hline Project Name & 2019-2021 & $\mathbf{2 0 2 2 - 2 0 2 4}$ & $\mathbf{2 0 2 5 - 2 0 2 7}$ & $\mathbf{2 0 2 8 - 2 0 3 0}$ \\
\hline Mountain afforestation & 980.42 & 300 & 286 & 250 \\
Returning farmland to forest & 260 & 100 & 100 & 100 \\
Forest afforestation & 433.08 & 150 & 140 & 120 \\
Afforestation subsidy project afforestation & 400 & 100 & 96 & 80 \\
Total & 2073.5 & 650 & 622 & 550 \\
\hline
\end{tabular}

order to increase the urban forest coverage area and the cooling area of urban forest patches, it is necessary to make full use of the urban gray space to improve the urban forest coverage rate, occupy a large number of urban land space to plan and construct forest patches, and expand the development direction of urban greening. In addition, in order to compound greening, different land types, community structure and tree species composition will produce different environmental effects, so it is essential to rationally select vegetation species of different levels, utilize limited patch space, increase space greening amount, and improve surface cooling effect. Suitable vegetation types should be selected, with trees or ornamental plants with the ability of cooling and humidification for residential vegetation and roadside vegetation. The government departments should also set a reasonable indicator of urban vegetation coverage rate, and the vegetation coverage rate should be faster than the growth rate of urban buildings and population; optimize the management and control requirements of vegetation planning, and in addition to retaining the original vegetation and green space planning, strengthen the vegetation of each land to meet the standards. The government can also expand the planning area of urban forests, reduce the intensity of heat island effect, and realize the sustainable development of urban ecological environment by implementing the mechanism of green subsidy and reward, optimizing urban laws and regulations, and expanding the way of green publicity.

\section{Conclusions}

Based on the study of urban heat island effect, this paper systematically plans the green space pattern of Shijiazhuang City and puts forward the optimization strategies in the view of the ecological benefits of urban forests. The concrete conclusions are as follows:

(1) The urban forests can buffer the ground cooling, but the heat island effect is obvious in the area far away from the urban forests due to the influence of the urban planning distribution structure and the vegetation coverage area, and the thermal effect space can be improved by changing the urban forest pattern.

(2) In order to maximize the benefits of urban forests, it is necessary to design the patch shape of the planning area reasonably, and increase the urban forest patch shape index, thereby increasing the coupling degree of forest vegetation and environment, and maximizing the reduction of heat island effect.

(3) It is feasible to increase urban forest coverage rate and reduce heat island effect. It is necessary to increase forest area from urban planning, optimization of vegetation type and community structure and government level so as to realize sustainable development of urban ecological environment. 
(4) The planning and design of forest cities is a long-term work. At present, there is no relevant data and theoretical research is not mature, so the remote sensing can be used to retrieve surface temperature to analyze the heat island effect of forest cities in the future.

\section{REFERENCES}

[1] Ahmed, A. Q., Ossen, D. R., Jamei, E., Manaf, N. A., Said, I., Ahmad, M. H. (2015): Urban surface temperature behaviour and heat island effect in a tropical planned city. Theoretical and Applied Climatology 119(3-4): 493-514.

[2] Gago, E. J., Roldan, J., Pacheco-Torres, R., Ordóez, J. (2013): The city and urban heat islands: a review of strategies to mitigate adverse effects. - Renewable and Sustainable Energy Reviews 25: 749-758.

[3] Hyoungsub, K., Donghwan, G., Yong, K. H. (2018): Effects of urban heat island mitigation in various climate zones in the United States. - Sustainable Cities and Society 41(8): 841-852.

[4] Jay, M., Schraml, U. (2013): Managing city forests for or in spite of recreation? perspectives of forest managers. - European Journal of Forest Research 132(1): 93-105.

[5] Kamruzzaman, M., Deilami, K., Yigitcanlar, T. (2018): Investigating the urban heat island effect of transit oriented development in Brisbane. - Journal of Transport Geography 66: 116-124.

[6] Krüger, E., Emmanuel, R. (2013): Accounting for atmospheric stability conditions in urban heat island studies: the case of Glasgow, UK. - Landscape and Urban Planning 117: 112-121.

[7] Li, G., Zhang, X., Mirzaei, P. A., Zhang, J., Zhao, Z. (2018): Urban heat island effect of a typical valley city in china: responds to the global warming and rapid urbanization. Sustainable Cities and Society 38(4): 736-745.

[8] Madanian, S., Costa, C. S. (2017): A model for evaluating a greenbelt planning in the city of Qazvin (Iran) using Micmac method. - Modeling Earth Systems \& Environment 3(4): 1503-1513.

[9] Senanayake, I. P., Welivitiya, W. D. D. P., Nadeeka, P. M. (2013): Remote sensing based analysis of urban heat islands with vegetation cover in Colombo City, Sri Lanka using Landsat-7 ETM+ data. - Urban Climate 5: 19-35.

[10] Wang, Y., Berardi, U., Akbari, H. (2015): Comparing the effects of urban heat island mitigation strategies for Toronto, Canada. - Energy and Buildings 114: 2-19.

[11] Weilin, L., Xiaoping, L., Dagang, W., Yanling, S. (2017): The impact of energy consumption on the surface urban heat island in China's 32 major cities. - Remote Sensing 9(3): 250.

[12] Wonorahardjo, S. (2012): New concepts in districts planning, based on heat island investigation. - Procedia Social and Behavioral Sciences 36: 235-242. 